\title{
Mitochondrial DNA content in paired normal and cancerous breast tissue samples from patients with breast cancer
}

\author{
Alex Xiu-Cheng Fan • Ramin Radpour • \\ Mahdi Montazer Haghighi · Corina Kohler • Peng Xia · \\ Sinuhe Hahn · Wolfgang Holzgreve $\cdot$ Xiao Yan Zhong
}

Received: 19 May 2008 / Accepted: 8 December 2008 / Published online: 6 January 2009

(C) Springer-Verlag 2008

\begin{abstract}
Introduction We develop a multiplex quantitative realtime PCR for synchronized analysis of mitochondrial DNA (mtDNA) and nuclear DNA (nDNA) to investigate relative mtDNA abundance in paired normal and cancerous breast tissues.

Materials and methods The amounts of nDNA and mtDNA in 102 tissue samples were quantified for both glyceraldehype-3-phosphodehydrogenase (GAPDH) gene and mtDNA encoded ATPase (MTATP) 8 gene. The average threshold cycle $(\mathrm{Ct})$ number values of the nDNA and mtDNA were used to calculate relative mtDNA content in breast tissues.

Results The median delta $\mathrm{Ct}(\Delta \mathrm{Ct})$ and the median mtDNA content for normal and cancerous breast tissues were 6.73 and 2.54 , as well as 106.50 and $5.80(P=0.000$, respectively). The mtDNA content was decreased in $82 \%$ of cancerous breast tissues compared with the normal ones. The changes were associated with hormone receptor status. Conclusion Our finding suggests that decreased mtDNA content in breast cancer may have diagnostic and prognostic value for the disease.
\end{abstract}

A. X.-C. Fan - R. Radpour - C. Kohler · P. Xia · S. Hahn ·

W. Holzgreve $\cdot$ X. Y. Zhong $(\square)$

Laboratory for Prenatal Medicine and Gynecologic Oncology,

Department of Biomedicine, Women's Hospital,

University of Basel, Hebelstrasse 20,

Room Nr. 416, 4031 Basel, Switzerland

e-mail: xzhong@uhbs.ch

M. M. Haghighi

Azad University, East of Tehran Branch, Tehran, Iran

W. Holzgreve

University Medical Center, University of Freiburg,

Hugstetter Str. 49, 79106 Freiburg, Germany
Keywords Quantitative alteration · Mitochondrial DNA . Breast cancer $\cdot$ Breast tissue

\section{Introduction}

Human cells have a nuclear genome and additional cytoplasmic genomes that are compartmentalised in the mitochondria. In comparison to nuclear genomic DNA, mitochondrial DNA (mtDNA) reveals high mutation rates caused by constant exposure to mutagenic oxygen radicals and lacks the protective mechanisms of DNA repair. These properties of mtDNA suggest their potential importance in ageing, apoptosis and especially carcinogenesis (Zhang and Qi 2008; Zhang et al. 2008).

Qualitative aberrations of mtDNA, such as mutations, have been found in solid tumours, such as colon, stomach, liver, kidney, bladder, prostate, skin and lung cancer (Copeland et al. 2002; Penta et al. 2001), and in haematological malignancies, such as leukaemia and lymphoma (Fontenay et al. 2006). Quantitative aberrations of mtDNA have been observed in various sample types from patients with cancers (Mambo et al. 2005). While increased mtDNA content has been found in prostate (Mizumachi et al. 2008a), head and neck (Kim et al. 2004), endometrial adenocarcinoma (Wang et al. 2005), etc., reduced mtDNA content in renal (Meierhofer et al. 2004) and liver cancers (Yin et al. 2004) has been reported.

Because of these mutations and the quantitative aberrations involved in the development of human cancers, mtDNA may have promising clinical applications for cancers (Jiang et al. 2005; Jain 2007). Decreased mitochondrial DNA copy number is correlated with tumour progression and prognosis in Chinese breast cancer patients ( $\mathrm{Yu}$ et al. 2007). Increased mtDNA content in saliva is associated 
with head and neck cancer (Mizumachi et al. 2008b). High levels of cell free circulating mtDNA in prostate cancer patients with poor prognosis could be a valuable predictor of prognosis (Ellinger et al. 2008; Mehra et al. 2007). Furthermore, mtDNA aberrations play important roles in response to cancer therapy, for example, causing resistance to therapeutic agents (Mizumachi et al. 2008b; Chen et al. 2007).

In the present study, we developed a simple and accurate multiplex real-time PCR method for synchronised quantification of nuclear DNA (nDNA) and mtDNA in paired adjacent normal and cancerous breast tissue samples from 51 patients with breast cancer. The content of MTATP8 gene on mtDNA in the cancerous tissues was compared with that in normal tissues from the same patients. We analysed the correlation between the content of mtDNA in tissues and the traditional pathological parameters and clinical predictive markers.

\section{Materials and methods}

\section{Samples}

The study was approved by the local institutional review board. Paraffin-embedded sections from adjacent normal and cancerous breast tissue samples were examined by two experienced pathologists. Breast cancer characteristics, the histological grading; hormone receptor status and biomarkers from the breast cancer patients are listed in Table 1 . DNA was extracted from three to five sections of each $10 \mu \mathrm{m}$ thick paraffin-embedded sample (around 0.01$0.02 \mathrm{~g}$ of tissue) using a High Pure PCR Template Preparation Kit (Roche Diagnostics, Germany) and eluted into $150 \mu \mathrm{l}$ of elution buffer. The eluted DNA was stored at $-20^{\circ} \mathrm{C}$ until further use.

\section{Real-time PCR}

The amounts of nDNA and mtDNA were quantified by multiplex TaqMan real-time PCR for both GAPDH gene of nDNA and MTATP 8 gene of mtDNA starting at locus 8446. The GAPDH and MTATP 8 primer and probe sequences are shown as follows: GAPDH (forward):5' CCC CAC ACA CAT GCA CTT ACC $3^{\prime}$; (reverse): 5'CCT AGT CCC AGG GCT TTG ATT $3^{\prime}$; probe $5^{\prime}$ (MGB) TAG GAA GGA CAG GCA AC (VIC) $3^{\prime}$. MTATP 8 (forward): 5' AAT ATT AAA CAC AAA CTA CCA CCT ACC $3^{\prime}$; (reverse): 5' TGG TTC TCA GGG TTT GTT ATA $3^{\prime}$; probe: $5^{\prime}$ (MGB) CCT CAC CAA AGC CCA TA (FAM) 3'.

The PCR was performed using the ABI PRISM 7000 Sequence Detection System (Applied Biosystems, ABI). A total of $2.5 \mu \mathrm{l}$ of DNA were used as template for the PCR analysis. The real-time PCR were carried out in $25 \mu \mathrm{l}$ of total reaction volume using a 2 min incubation at $50^{\circ} \mathrm{C}$, followed by an initial denaturation step at $95^{\circ} \mathrm{C}$ for $10 \mathrm{~min}$ and 40 cycles of $1 \mathrm{~min}$ at $60^{\circ} \mathrm{C}$ and $15 \mathrm{~s}$ at $95^{\circ} \mathrm{C}$.

To determine the quantities of mtDNA and nDNA present in tissue samples, standard dilution curves using HPLCpurified single-stranded synthetic DNA oligonucleotides (Microsynth) specifying a 79-bp MTATP 8 gene amplicon and a 97-bp GAPDH amplicon with concentration ranging from $5 \times 10^{7}$ copies to $5 \times 10^{2}$ copies, were used. We examined the amplification efficiency for both GAPDH and MTATP 8 on experimental serial dilutions. The amplifications of mtDNA and nDNA on serial dilutions showed a good correlation with comparable efficiencies. A threshold cycle $(\mathrm{Ct})$ reflects the cycle number at which a fluorescence signal within a reaction crosses a threshold. In our study, the average threshold cycle number $(\mathrm{Ct})$ values of the nDNA and mtDNA were obtained from each case. The content of mtDNA was calculated using the delta $\mathrm{Ct}(\Delta \mathrm{Ct})$ of average $\mathrm{Ct}$ of mtDNA and nDNA $(\Delta \mathrm{Ct}=\mathrm{CtnDNA}-$ CtmtDNA $)$ in the same well as an exponent of $2\left(2^{\Delta \mathrm{Ct}}\right)$.

Statistical analysis

The data were analysed using SPSS software (Statistical Software Package for Windows v. 15.0). Content of mtDNA is given as the median, the range and the fold difference. Wilcoxon signed ranks test was used to compare the differences between ranks of each paired samples. The Mann-Whitney $U$ test and Kruskal-Wallis test was used to compare the content of mtDNA in normal adjacent normal tissues and cancerous tissues. The Spearman rank test was applied to analyse the relationship of mtDNA content between normal tissues and cancerous tissues.

\section{Results}

Co-extraction of mtDNA and nDNA from the paired breast tissue samples

Nuclear DNA and mtDNA were co-extracted from the paraffin-embedded sections. The average $\mathrm{Ct}$ values for GAPDH sequence, representing total nDNA, ranged from 24.42 to 37.08 in cancerous tissues and from 25.19 to 38.38 in normal tissues, respectively. The average $\mathrm{Ct}$ values for MTATP 8 gene sequence, representing total mtDNA, ranged from 18.48 to 32.54 in cancerous tissues and from 19.28 to 33.42 in normal tissues, respectively. The average $\mathrm{Ct}$ values of mtDNA were less than those of nDNA in all cases, represented higher amounts of mtDNA than those of nDNA in the breast tissues. While the average $\mathrm{Ct}$ values of GAPDH amplification in the normal tissues are correlated with those of MTATP8 gene amplification (Spearman rank 
Table 1 Patients data as well as relationships between decreased content of mtDNA in cancerous tissues and clinical factors

\begin{tabular}{|c|c|c|c|}
\hline Variables & Group (cases) & mtDNA content & $P$ value \\
\hline \multirow[t]{2}{*}{ Age } & $<50(32)$ & $195.36(6.70-2,460.95)$ & \multirow[t]{2}{*}{$0.596^{*}$} \\
\hline & $\geq 50(19)$ & $23.48(6.43-284.05)$ & \\
\hline \multirow[t]{2}{*}{ Histological type } & Ductal (41) & $53.82(1.35-9,877.98)$ & \multirow[t]{2}{*}{$0.337 *$} \\
\hline & Lobular (10) & $201.39(7.31-823.14)$ & \\
\hline \multirow[t]{3}{*}{ Primary tumour } & $\mathrm{T} 1(23)$ & $149.09(6.43-749.61)$ & \multirow[t]{3}{*}{$0.824 *$} \\
\hline & $\mathrm{T} 2(15)$ & $23.48(6.70-861.08)$ & \\
\hline & T3 (9) & $2382.54(2,304.12-2,460.95)$ & \\
\hline \multirow[t]{2}{*}{ Lymph node involvement } & Positive (41) & $149.09(6.43-2,460.95)$ & \multirow[t]{2}{*}{$0.201 *$} \\
\hline & Negative (9) & $57.82(9.48-106.15)$ & \\
\hline \multirow[t]{2}{*}{ Distant metastasis } & M0 (40) & $137.44(6.70-2,460.95)$ & \multirow[t]{2}{*}{$0.585^{*}$} \\
\hline & M1 (10) & $53.82(6.43-584.07)$ & \\
\hline \multirow[t]{4}{*}{ Stage } & $\mathrm{I}(5)$ & $57.82(9.48-106.15)$ & \multirow[t]{4}{*}{$0.140 *$} \\
\hline & II (27) & $137.44(6.70-861.08)$ & \\
\hline & III (6) & $2382.54(2,304.12-2,460.95)$ & \\
\hline & IV (9) & $53.82(6.43-584.07)$ & \\
\hline \multirow[t]{3}{*}{ Histological grading } & G1 (8) & $397.97(9.48-2,460.95)$ & \multirow[t]{3}{*}{$0.696^{* *}$} \\
\hline & G2 (19) & $195.36(6.43-861.08)$ & \\
\hline & G3 (15) & $34.22(7.31-225.97)$ & \\
\hline \multirow[t]{3}{*}{ Nuclear grading } & $1(3)$ & $57.82(9.48-106.15)$ & \multirow[t]{3}{*}{$0.418^{* *}$} \\
\hline & $2(14)$ & $195.36(9.99-2,304.12)$ & \\
\hline & $3(16)$ & $137.44(6.43-2,460.95)$ & \\
\hline \multirow[t]{2}{*}{ ER } & Positive (14) & $12.46(1.18-69,272.73)$ & \multirow[t]{2}{*}{$0.613^{*}$} \\
\hline & Negative (18) & $6.57(1.18-8,451.55)$ & \\
\hline \multirow[t]{2}{*}{ PR } & Positive (18) & $20.83(1.18-69,272.73)$ & \multirow[t]{4}{*}{$0.037 *$} \\
\hline & Negative (14) & $3.77(1.18-394.81)$ & \\
\hline \multirow[t]{2}{*}{ Her2 } & Positive (15) & $53.82(6.70-2,460.95)$ & \\
\hline & Negative (17) & $210.67(6.43-2,304.12)$ & \\
\hline \multirow[t]{2}{*}{ P53 } & Positive (3) & $1205.14(106.15-2,304.12)$ & \multirow[t]{2}{*}{$0.153^{*}$} \\
\hline & Negative (29) & $125.80(6.43-2,460.95)$ & \\
\hline \multirow[t]{2}{*}{ PS2 } & Positive (11) & $106.15(6.43-2,304.12)$ & \multirow[t]{2}{*}{$0.699 *$} \\
\hline & Negative (20) & $137.44(6.70-2,460.95)$ & \\
\hline \multirow[t]{2}{*}{ Ki62 } & Positive (0) & & \\
\hline & Negative (31) & $125.80(6.43-2,460.95)$ & \\
\hline
\end{tabular}

test $P<0.001, r=0.63$ ) (Fig. 1a), no similar phenomenon was observed in cancerous tissues $(P>0.05, r=0.261)$ (Fig. 1b), suggesting an alteration of the relationship between nDNA and mtDNA in cancerous tissues.

Content of mtDNA in paired normal and cancerous breast tissues

The $\Delta \mathrm{Ct}$ values between GAPDH amplification and MTATP 8 gene amplification show a 6.73 cycle difference in normal tissues and 2.54 cycle difference in cancerous tissues. The $\Delta \mathrm{Ct}$ values between normal and cancerous tissues shows a 4.2 cycle difference $(\Delta \Delta \mathrm{Ct})$ (Mann-Whitney $U$ test $P<0.001$ ) (Table 2). We calculated the content of mtDNA in the tissues using a formula of $2^{\Delta \mathrm{Ct}}$. The content of
mtDNA in cancerous tissues is significantly lower than that in normal tissues (Mann-Whitney $U$ test $P<0.001$ ) (Fig. 2). Out of 51 paired samples, 42 pairs show mtDNA in normal tissues $>$ mtDNA in cancerous tissues (Wilcoxon signed ranks test $P<0.001)$.

Relationship between decreased content of mtDNA and other established prognostic factors

In this study, associations between the content of mtDNA in breast tissues and traditional clinical parameters, such as age, tumour type, tumour size, lymph node involvement, extent of metastasis, stage, histological grading, receptor status and pathological biomarkers (HER-2/neu and PS2), were analysed (Table 1). 

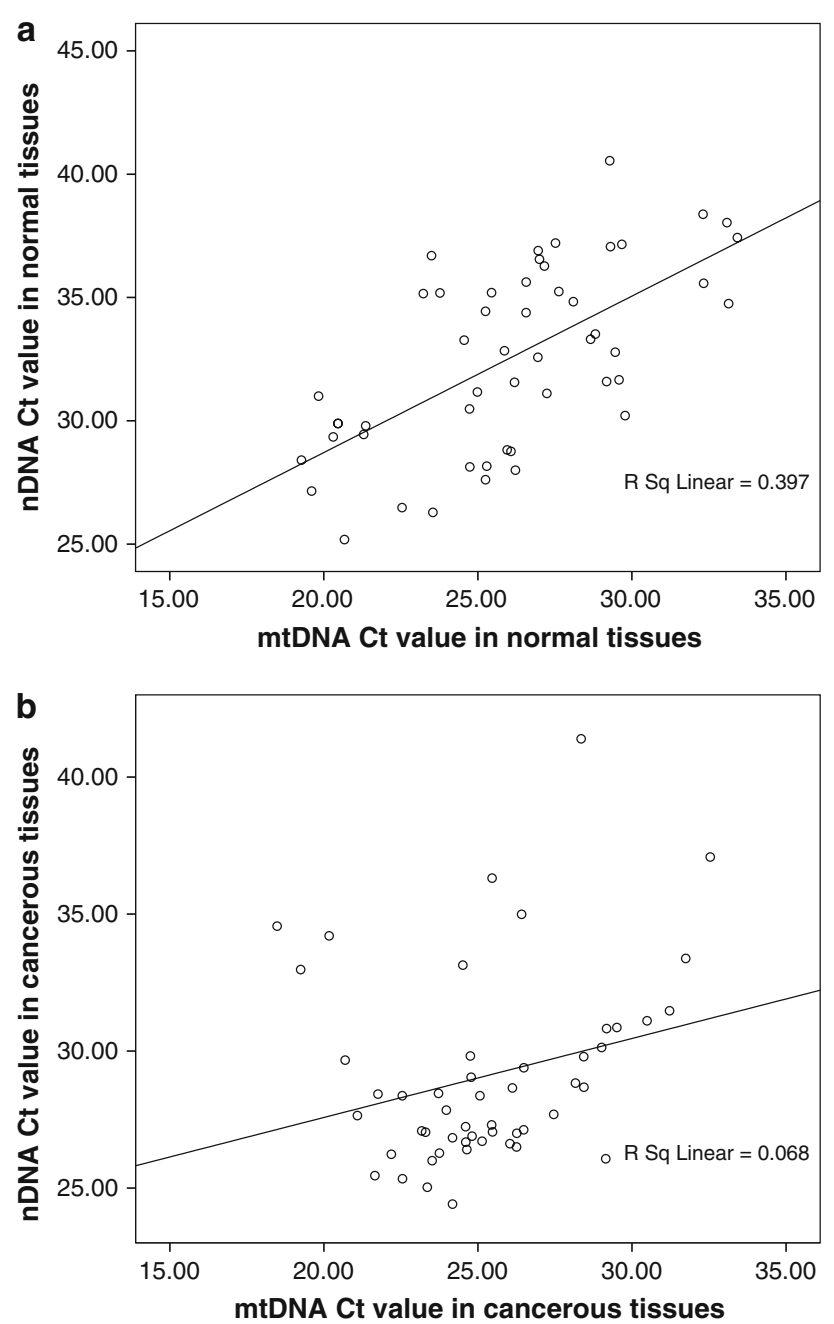

Fig. 1 a mtDNA amplifications are correlated with nDNA amplifications in normal tissues $(P=0.000, r=0.63)$; $\mathbf{b}$ mtDNA amplifications are not correlated with nDNA amplifications in cancerous tissues $(P=0.065, r=0.261)$

Decreased content of mtDNA in breast cancer was not associated with age ( $\geq 50$ vs. $<50$ ), tumour type (ductal vs. lobular), tumour size (T1, T2, T3), lymph node involvement (N0 and N1), extent of metastasis (M0 vs. M1), stage,

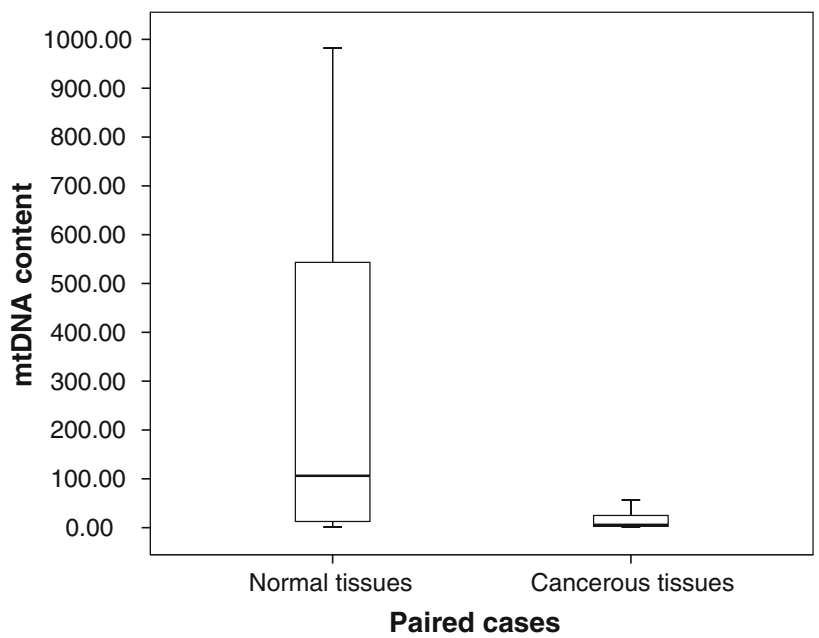

Fig. 2 mtDNA content in paired adjacent normal and cancerous breast tissues

histological grading (I, II, III), HER-2/neu amplifications and PS2 detections (Table 1). However, while we found significantly decreased mtDNA content in normal tissues of an oestrogen receptor (ER) negative detection compared with that of an ER positive detection (mtDNA in normal tissues 89.81 vs. $756.46, P=0.041$; mtDNA in cancerous tissues 6.57 vs. $12.46, P=0.613$ ) (Fig. 3a), a significantly decreased content of mtDNA in both normal and cancerous tissues of a progesterone receptor (PR) negative detection compared with that of PR positive tissues was observed (mtDNA in normal tissues 37.67 vs. 434.06, $P=0.016$; mtDNA in cancerous tissues 3.77 vs. 20.83, $P=0.037$ ) (Fig. 3b).

\section{Discussion}

In this study, we found that mtDNA content of MTATP 8 gene for encoding ATP synthase was decreased in 42 of 51 ( $82 \%$ ) cancerous breast tissues compared to their normal breast tissues collected from same individuals (Table 2).

Table 2 Comparison of mtDNA content in normal and cancerous breast tissues

\begin{tabular}{lllll}
\hline & Normal (N) 51 & Cancerous (C) 51 & Fold & $\begin{array}{l}\text { Significances/ } \\
\text { correlation }(P \text { value })\end{array}$ \\
\hline$\Delta \mathrm{CT}=\mathrm{Ct}_{\mathrm{nDNA}}-\mathrm{CtmtDNA}$ & 6.73 & 2.54 & $\Delta \Delta \mathrm{CT}$ : & $0.000^{*}$ \\
$\mathrm{Content}=2^{\Delta \mathrm{CT}}$ & $0.43-13.27$ & $0.23-16.08$ & $6.73-2.54=4.2$ & $0.000^{*}$ \\
$\mathrm{~N}>\mathrm{C}$ or $\mathrm{C}>\mathrm{N}$ & 106.20 & 5.80 & Fold & $0.242 * *(\mathrm{C}: \mathrm{N})$ \\
Correlation $\left(\mathrm{Ct}_{\mathrm{nDNA}}: \mathrm{Ct}_{\mathrm{mtDNA}}\right)$ & $1.30-9877.90$ & $1.20-69272.70$ & $106.20 / 5.80=18.3$ & $0.000^{* * *}$ \\
& 42 & 9 & & \\
& $r=0.63$ & $* * P=0.065$ & & \\
\hline
\end{tabular}

* Mann-Whitney $U$ test; ** Spearman Rank test; *** Wilcoxon Signed Ranks test 

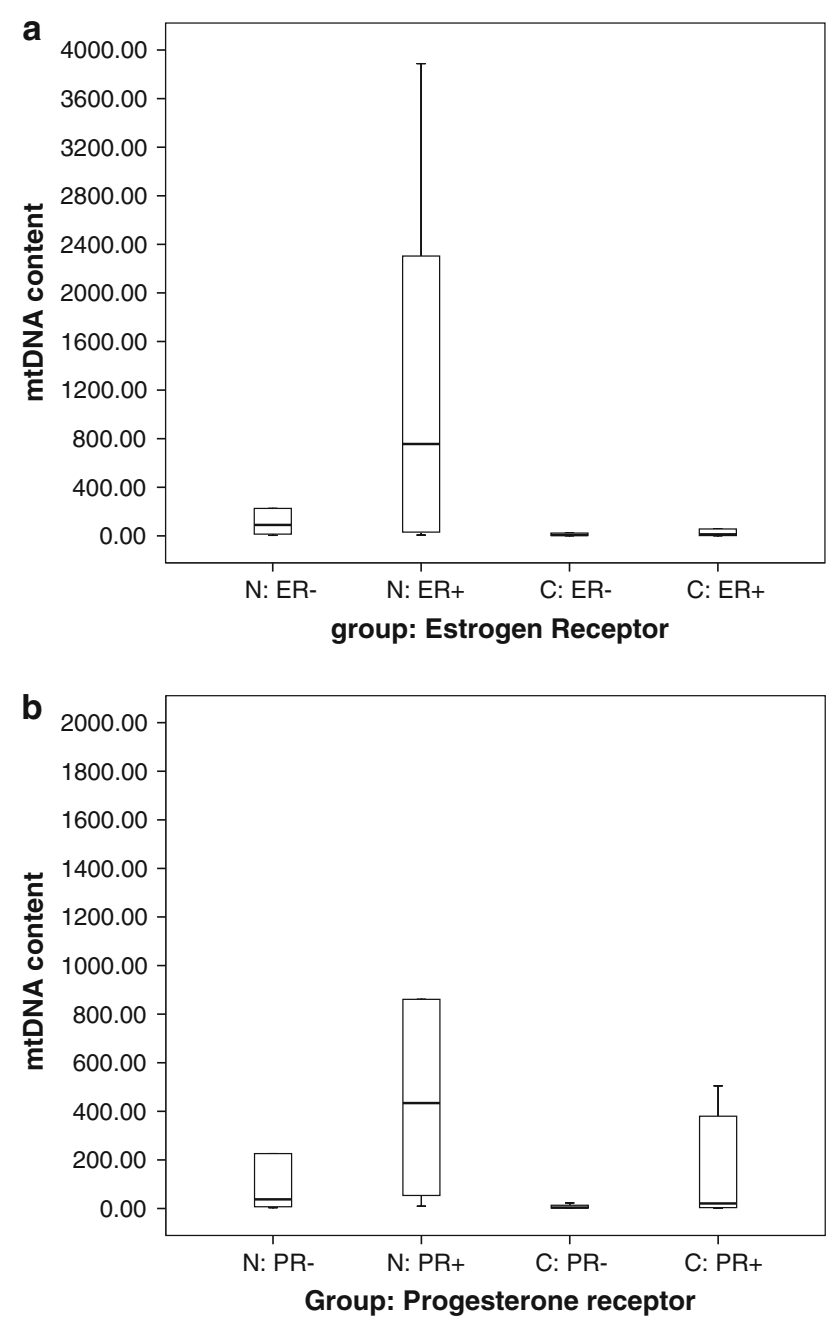

Fig. 3 a mtDNA content in ER positive and ER negative normal and cancerous tissues; $\mathbf{b}$ mtDNA content in PR positive and PR negative normal and cancerous tissues. ER+ estrogen receptor positive, $E R-$ estrogen receptor negative, $N$ normal tissues, $C$ cancerous tissues, $P R+$ progesterone receptor positive, $P R-$ progesterone receptor negative

Using different primers and methods to amplify different regions on mtDNA, Yu et al. (2007) (on D-loop), Mambo et al. (2005) (on Co I region) and Tseng et al. (2006) (on ND1 gene) found the similar phenomenon. This suggests that, as it has been reported for other cancer types, quantitative alterations of mtDNA may be a potential biomarker for breast cancer. Both decrease and increase of mtDNA content in cancers have been shown in many studies, varying with tissue type or origin of tumours, because of different patterns of mitochondrial transcripts coding for proteins involved in oxidative phosphorylation (Lebrecht et al. 2005; Masuyama et al. 2005).

Decrease of mtDNA has been observed in renal cancer (Meierhofer et al. 2004) and hepatocellular carcinoma (Yin et al. 2004). However, the pathogenesis of mtDNA decrease in cancers remains unclear. It was hypothesised that mitochondrial respiratory dysfunction and damage of
mtDNA, such as mutation, deletion or depletion, in carcinogenesis may course the quantitative alterations (Ye et al. 2008). Those alterations of mtDNA could correlate with increased risk (Mosquera-Miguel et al. 2008; Bai et al. 2007) and increased invasiveness of cancer (Simonnet et al. 2002). Decreased mtDNA content can cause decreased oxidative phosphorylation capacity that could increase cancer cell growth under hypoxic conditions during cancer development and cancer progression (Rossignol et al. 2004). Depletion of mtDNA can also lead to cells resistant to a certain apoptosis pathway during cancer development (Higuchi 2007).

In our study, mtDNA content was significantly decreased in cancerous breast tissues. However, high copy numbers of mtDNA per cell compared to those of nDNA (from $2^{2.535}$ to $2^{6.73}$ is from 5.8- to 106.2-fold higher in our study) may still increase the sensitivity of testing mtDNA alterations, thus having more promising clinical applications in cancers.

Using QuantiTest SYBR Green PCR, Yu et al. (2007) found that, on a 59 case study, mtDNA copy number alteration is correlated with tumour progression and prognosis in Chinese breast cancer patients. They showed that the reduced copy number in mtDNA was associated with an older onset age ( $\geq 50$ years old) and a higher histological grade. We compared the decrease in mtDNA content with other traditional clinical parameters, such as age, tumour size, lymph node involvement, extent of metastasis, and predictive markers, such as histological grades, HER-2/neu amplification and PS2 detection. No relationship was found between the decrease and those parameters. It was likewise shown by Mambo et al. (2005) that changes in mtDNA content in breast cancer did not correlate with tumour grade and metastasis, suggesting that these alterations may occur in the early stages of tumorigenesis.

However, in our study, we did find associations between mtDNA content and hormone receptor status. MtDNA content is significantly higher in ER positive normal breast tissues than that in ER negatives, suggesting that ER status in normal breast tissue may play a part in mtDNA function. Chen et al. (2004) observed that ER is present in mitochondria of human MCF7 cells, implying that oestrogens can have an effect on mitochondrial via ER in regulation of mitochondrial respiratory chain structure and function (Chen et al. 2005; Yager and Chen 2007). A similar phenomenon was not shown in the cancerous tissues. We presume that mtDNA dependent ER action may be altered during cancer development in vivo.

In our study, we also observed that changes in mtDNA content are associated with PR in both normal and cancerous tissues (mtDNA in PR positive $>$ that in PR negative). We assume that the changes may be tissue specific rather than tumour specific. Several studies showed that mitochondria respiration varies during the menstrual cycle and 
is associated with pregnancy (Buffenstein et al. 1995; Webb 1986). Mitochondria respiration increases during the progesterone-dominant lucteal phase.

In conclusion, our data suggest that using a robust Taqman real-time PCR, the content of mtDNA in breast tissues can be easily quantified. MtDNA content in breast cancer tissues decreased dramatically, and the changes are not associated with most traditional prognostic parameters. Many studies in vitro, using animal models and cell culture models, showed that reduced mtDNA content could lead to cells resistant to apoptosis, favour cancer cell growth, increase invasiveness and contribute to progression and metastasis of cancer cells. Therefore, decrease of mtDNA content in breast cancer may have diagnostic and prognostic value. In this study, we also found hormone receptor related changes in mtDNA content, which may assist us in understanding the biology of mtDNA in gender and age manner.

Acknowledgments This work was supported in part by Swiss National Science Foundation (320000-119722/1), Swiss Cancer League, Krebsliga Beider Basel and Dr. Hans Altschueler Stiftung. We thank Mrs Vivian Kiefer and Mrs Nicole Chiodetti for their help. We are grateful to Mrs Regan Geissmann for proofreading the text.

\section{References}

Bai RK, Leal SM, Covarrubias D, Liu A, Wong LJ (2007) Mitochondrial genetic background modifies breast cancer risk. Cancer Res 67:4687-4694. doi:10.1158/0008-5472.CAN-06-3554

Buffenstein R, Poppitt SD, McDevitt RM, Prentice AM (1995) Food intake and the menstrual cycle: a retrospective analysis, with implications for appetite research. Physiol Behav 58:1067-1077. doi:10.1016/0031-9384(95)02003-9

Chen JQ, Delannoy M, Cooke C, Yager JD (2004) Mitochondrial localization of ERalpha and ERbeta in human MCF7 cells. Am J Physiol Endocrinol Metab 286:E1011-E1022. doi:10.1152/ ajpendo.00508.2003

Chen JQ, Yager JD, Russo J (2005) Regulation of mitochondrial respiratory chain structure and function by estrogens/estrogen receptors and potential physiological/pathophysiological implications. Biochim Biophys Acta 1746:1-17. doi:10.1016/j.bbamcr.2005. 08.001

Chen Z, Lu W, Garcia-Prieto C, Huang P (2007) The Warburg effect and its cancer therapeutic implications. J Bioenerg Biomembr 39:267-274. doi:10.1007/s10863-007-9086-x

Copeland WC, Wachsman JT, Johnson FM, Penta JS (2002) Mitochondrial DNA alterations in cancer. Cancer Invest 20:557-569. doi:10.1081/CNV-120002155

Ellinger J, Muller SC, Wernert N, von Ruecker A, Bastian PJ (2008) Mitochondrial DNA in serum of patients with prostate cancer: a predictor of biochemical recurrence after prostatectomy. BJU Int 102(5):628-632

Fontenay M, Cathelin S, Amiot M, Gyan E, Solary E (2006) Mitochondria in hematopoiesis and hematological diseases. Oncogene 25:4757-4767. doi:10.1038/sj.onc. 1209606

Higuchi M (2007) Regulation of mitochondrial DNA content and cancer. Mitochondrion 7:53-57. doi:10.1016/j.mito.2006.12.001

Jain KK (2007) Cancer biomarkers: current issues and future directions. Curr Opin Mol Ther 9:563-571
Kim MM, Clinger JD, Masayesva BG, Ha PK, Zahurak ML, Westra WH et al (2004) Mitochondrial DNA quantity increases with histopathologic grade in premalignant and malignant head and neck lesions. Clin Cancer Res 10:8512-8515. doi:10.1158/10780432.CCR-04-0734

Lebrecht D, Kokkori A, Ketelsen UP, Setzer B, Walker UA (2005) Tissue-specific mtDNA lesions and radical-associated mitochondrial dysfunction in human hearts exposed to doxorubicin. J Pathol 207:436-444. doi:10.1002/path.1863

Mambo E, Chatterjee A, Xing M, Tallini G, Haugen BR, Yeung SC et al (2005) Tumor-specific changes in mtDNA content in human cancer. Int J Cancer 116:920-924. doi:10.1002/ijc.21110

Masuyama M, Iida R, Takatsuka H, Yasuda T, Matsuki T (2005) Quantitative change in mitochondrial DNA content in various mouse tissues during aging. Biochim Biophys Acta 1723:302308

Mehra N, Penning M, Maas J, van Daal N, Giles RH, Voest EE (2007) Circulating mitochondrial nucleic acids have prognostic value for survival in patients with advanced prostate cancer. Clin Cancer Res 13:421-426. doi:10.1158/1078-0432.CCR-06-1087

Meierhofer D, Mayr JA, Foetschl U, Berger A, Fink K, Schmeller N et al (2004) Decrease of mitochondrial DNA content and energy metabolism in renal cell carcinoma. Carcinogenesis 25:10051010. doi:10.1093/carcin/bgh104

Mizumachi T, Suzuki S, Naito A, Carcel-Trullols J, Evans TT, Spring PM et al (2008a) Increased mitochondrial DNA induces acquired docetaxel resistance in head and neck cancer cells. Oncogene 27:831-838. doi:10.1038/sj.onc.1210681

Mizumachi T, Naito MLA, Furusawa J, Fan CY, Siegel ER et al (2008b) Increased distributional variance of mitochondrial DNA content associated with prostate cancer cells as compared with normal prostate cells. Prostate 68:408-417. doi:10.1002/ pros. 20697

Mosquera-Miguel A, Alvarez-Iglesias V, Carracedo A, Salas A, Vega A, Carracedo A et al (2008) Is mitochondrial DNA variation associated with sporadic breast cancer risk? Cancer Res 68:623-625. doi:10.1158/0008-5472.CAN-07-2385 author reply 624

Penta JS, Johnson FM, Wachsman JT, Copeland WC (2001) Mitochondrial DNA in human malignancy. Mutat Res 488:119-133. doi:10.1016/S1383-5742(01)00053-9

Rossignol R, Gilkerson R, Aggeler R, Yamagata K, Remington SJ, Capaldi RA (2004) Energy substrate modulates mitochondrial structure and oxidative capacity in cancer cells. Cancer Res 64:985-993. doi:10.1158/0008-5472.CAN-03-1101

Simonnet H, Alazard N, Pfeiffer K, Gallou C, Beroud C, Demont J et al (2002) Low mitochondrial respiratory chain content correlates with tumor aggressiveness in renal cell carcinoma. Carcinogenesis 23:759-768. doi:10.1093/carcin/23.5.759

Tseng LM, Yin PH, Chi CW, Hsu CY, Wu CW, Lee LM et al (2006) Mitochondrial DNA mutations and mitochondrial DNA depletion in breast cancer. Genes Chromosomes Cancer 45:629-638. doi: $10.1002 /$ gcc. 20326

Wang Y, Liu VW, Xue WC, Tsang PC, Cheung AN, Ngan HY (2005) The increase of mitochondrial DNA content in endometrial adenocarcinoma cells: a quantitative study using laser-captured microdissected tissues. Gynecol Oncol 98:104-110. doi:10.1016/ j.ygyno.2005.04.015

Webb P (1986) 24-hour energy expenditure and the menstrual cycle. Am J Clin Nutr 44:614-619

Yager JD, Chen JQ (2007) Mitochondrial estrogen receptors-new insights into specific functions. Trends Endocrinol Metab 18:8991. doi:10.1016/j.tem.2007.02.006

Ye C, Shu XO, Wen W, Pierce L, Courtney R, Gao YT et al (2008) Quantitative analysis of mitochondrial DNA 4977-bp deletion in sporadic breast cancer and benign breast diseases. Breast Cancer Res Treat 108:427-434. doi:10.1007/s10549-007-9613-9 
Yin PH, Lee HC, Chau GY, Wu YT, Li SH, Lui WY et al (2004) Alteration of the copy number and deletion of mitochondrial DNA in human hepatocellular carcinoma. Br J Cancer 90:2390-2396

Yu MZY, Shi Y, Ning L, Yang Y, Wei X et al (2007) Reduced mitochondrial DNA copy number is correlated with tumor progression and prognosis in Chinese breast cancer patients. IUBMB Life 59:450-457. doi:10.1080/15216540701509955
Zhang XN, Qi M (2008) Mitochondrion and its related disorders: making a comeback. J Zhejiang Univ Sci B 9:90-92. doi:10.1631/ jzus.B0710621

Zhang SP, Song SJ, Li YX (2008) Association between mitochondrial DNA mutations and cancer in human. Yi Chuan 30:263-268. doi:10.3724/SP.J.1005.2008.00263 